\title{
Liquid-Liquid Equilibrium of Poly(Ethylene Glycol) $6000+$ Sodium Succinate + Water System at Different Temperatures
}

\author{
Selvaraj Raja and Vytla Ramachandra Murty \\ Department of Biotechnology, Manipal Institute of Technology, Manipal, Karnataka 576104, India \\ Correspondence should be addressed to Selvaraj Raja; rajaselvaraj@gmail.com
}

Received 30 April 2013; Accepted 4 June 2013

Academic Editors: C. S. Bildea, E. Diaz, F. J. Keil, and F. Oktar

Copyright ( 2013 S. Raja and V. R. Murty. This is an open access article distributed under the Creative Commons Attribution License, which permits unrestricted use, distribution, and reproduction in any medium, provided the original work is properly cited.

Phase diagrams and the compositions of coexisting phases of poly(ethylene glycol) (PEG) $6000+$ sodium succinate + water system have been determined experimentally at $298.15,308.15$, and $318.15 \mathrm{~K}$. The effects of temperature on the binodal curve and tie lines have been studied. The binodal curves were successfully fitted to a nonlinear equation relating the concentrations of PEG 6000 and sodium succinate, and the coefficients were estimated for the formentioned systems (low AARD, high $R^{2}$, and low SD). Tie-line compositions were estimated and correlated using Othmer-Tobias and Bancroft equations, and the parameters were reported. The effect of temperature on the phase-forming ability has been studied by fitting the binodal data to a Setschenow-type equation for each temperature. The effective excluded volume (EEV) values were also calculated from the binodal data, and it was found out that the values increased with an increase in the temperature. Furthermore, the effect of MW of PEG on the phase diagram has been studied and verified.

\section{Introduction}

A liquid-liquid extraction method, Aqueous Two-Phase System (ATPS), comprised of a hydrophilic polymer and salt with water (polymer + salt + water) has been proved as a frugal and powerful method to separate and partially purify various biomolecules from the crude fermentation broth as compared to ATPS consists of two hydrophilic polymers with water (polymer + polymer + water) [1]. It has been shown by many researchers that this downstream processing method reduces the number of initial purification steps and thus decreases the overall processing cost [2-4]. Apart from conventional purification of biomolecules, ATPS also finds its applications in environmental remediation such as removal of color from textile effluents [5], metal removal from effluents [6], and recovery of biomolecules from various industrial effluents [7-10]. In our lab, we have established a citratebased ATPS to recover valuable biomolecules from tannery wastewater $[11,12]$.

The type of the phase components used affects the properties of an ATPS. Because of the salient features like low cost, ease of phase separation with salts, and enhancement of the refolding of proteins to recover the activity, poly(ethylene glycol) (PEG) is the most commonly used polymer in ATPS [13]. Now there is a considerable interest in using biodegradable salts with PEG to formulate ATPS instead of conventional inorganic salts like phosphates and sulfates. The presence of inorganic salts in the effluent imposes environmental pollution, and it can be avoided by using biodegradable salts like citrates, tartrates, and succinates for the formulation of ATPS [14].

Even though there is a significant research work done on PEG + citrate + water system, ATPS based on PEG + succinate + water system is very limited and is not explored much. According to our knowledge there are only three [15-17] reports available for PEG + succinate + water system. Ananthapadmanabhan and Goddard [15] reported binodal data for PEG 6000 + succinate + water at room temperature; ZafaraniMoattar and Hamzehzadeh [16] reported the binodal data and tie-line compositions of PEG 6000 + succinate + water at $298.15 \mathrm{~K}$; Perez et al. [17] studied the binodal behavior of PEG 6000 + succinate + water at $295.1 \mathrm{~K}$ and partitioning of various standard proteins. However, the data for other temperatures for these systems are not available in the literature. 
Development of any ATPS involves the phase diagram determination which gives the information about the concentration of phase forming components necessary to form two phases and the phase composition after the phase separation. This data is very much essential to design an ATPS for the separation and purification of biomolecules which may be used for single-stage extraction or multistage extraction processes [18].

Therefore the aim of the present study is to develop the unexplored, liquid-liquid equilibrium (LLE) data of PEG $6000+$ sodium succinate + water at different temperatures $298.15 \mathrm{~K}, 308.15 \mathrm{~K}$, and $318.15 \mathrm{~K}$ and tie-line compositions. The effect of temperature in the present system was discussed on the basis of salting-out coefficient and effective excluded volume and compared with the literature. The effect of molecular weight of PEG was also discussed.

\section{Materials and Methods}

2.1. Materials. PEG 6000 and PEG 10000 from Merck and sodium succinate heptahydrate from Loba chemicals, India were used for the present work. All the chemicals were used without further purification and Millipore-Milli-Q water was used in all the experiments.

2.2. Construction of Binodal Curve. Titration method [19] was used to obtain binodal curves. The experiments were carried out in a $100 \mathrm{~mL}$ jacketed glass vessel. The temperature of the working vessel was maintained at various temperatures with an uncertainty of $\pm 0.1 \mathrm{~K}$ (Refrigerated Circulating Bath, EQUIBATH, no. 85006) by circulating water through an external jacket. Aqueous stock solution of PEG 6000 of $40 \%$ $(\mathrm{w} / \mathrm{w})$ and sodium succinate of $30 \%(\mathrm{w} / \mathrm{w})$ were prepared and kept in a constant-temperature bath. After equilibration, a known amount of PEG stock solution was taken in the jacketed vessel and constantly stirred by a magnetic stirrer in order to maintain uniform concentration of the components of ATPS. A known amount of the salt solution was added drop-wise to the PEG solution or vice versa, in the jacketed vessel till the appearance of turbidity, which indicated the two-phase formation. To this two-phase solution, water was then added drop-wise until the disappearance of turbidity (single phase). The procedure was repeated to get enough binodal points. An analytical balance with a precision of $\pm 0.1 \mathrm{mg}$ (Shimadzu Analytical Balance, Japan, Model: AUW120D) was used to determine the composition of the mixture. All the experiments were done in duplicates and average values were reported.

2.3. Determination of Tie-Line Length and Composition. For the determination of tie-line composition, a series of ATPSs of known total compositions were prepared in graduated $15 \mathrm{~mL}$ centrifuge tubes and placed in the thermostatic water bath at various temperatures. The solution was rigorously mixed in a vortex mixer for $10 \mathrm{~min}$. This mixture was equilibrated for $24 \mathrm{~h}$ in the thermostatic water bath at the specified temperatures. The two individual phases were carefully separated and the concentration of sodium ions in the top and bottom phases was determined by flame photometry

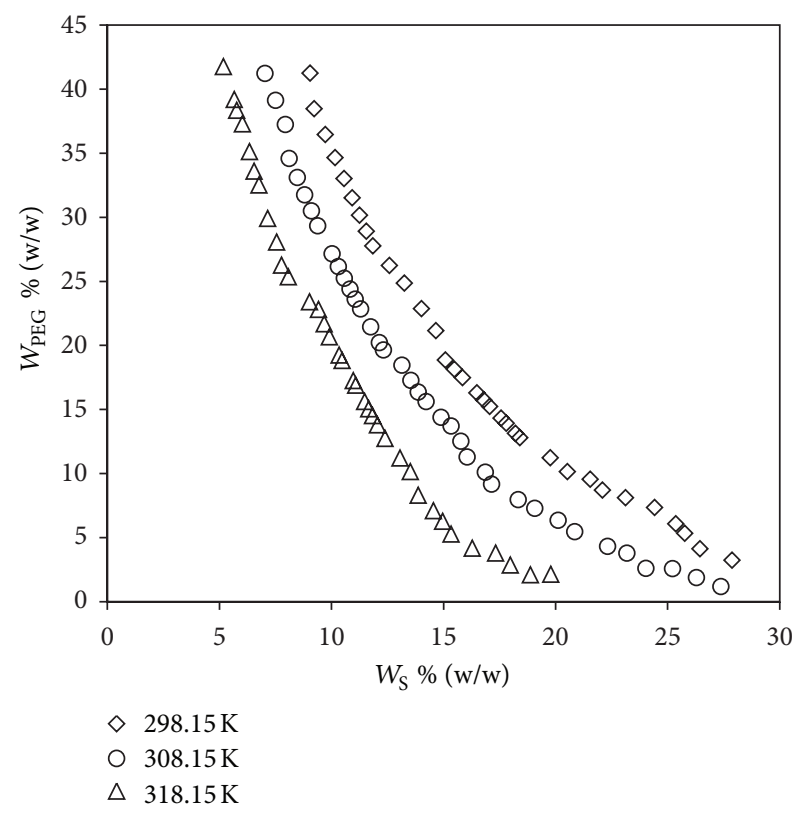

FIGURE 1: Effect of the temperature on the location of binodal curves for the PEG $6000\left(W_{\mathrm{PEG}}\right)+$ sodium succinate $\left(W_{\mathrm{S}}\right)+$ water systems.

(Systronics128 flame photometer). The uncertainty of the mass fraction of the salt was within \pm 0.002 . The equilibrium concentration of PEG in both phases was determined by refractive index measurements using an Abbe-type refractometer (Advance Research Instruments Co., New Delhi, Model R-4) with a precision of \pm 0.0001 . Samples were properly diluted in such a way that the concentration would fall within the linear range of calibration.

\section{Results and Discussions}

3.1. Binodal Curve. The region below the binodal curve represents single-phase and above it represents two-phase region, and thus a binodal curve is a boundary line between them. The binodal data obtained by the titration method for PEG 6000 + sodium succinate + water systems at various temperatures are given in Table 1 and are shown schematically in Figure 1.

There are several correlations available in the literature to correlate with the binodal data [20-22].

However, the nonlinear equation (1) proposed by $\mathrm{Hu}$ et al. [23] was best fitted for the present experimental data. Consider

$$
W_{\mathrm{PEG}}=A+B W_{\mathrm{S}}^{0.5}+C W_{\mathrm{S}}+D W_{\mathrm{S}}^{2},
$$

where $W_{\text {PEG }}$ and $W_{S}$ are the weight percentages of PEG and sodium succinate, respectively. $A, B, C$, and $D$ are the fitted parameter coefficients. The fitted coefficients are shown in Table 2. The high regression coefficient $\left(R^{2}\right)$ values, less average arithmetic relative deviation (AARD), and standard deviation $(\mathrm{SD})$ values suggest that the experimental data are well fitted with the correlations. 
TABLE 1: Binodal data for the PEG $6000+$ sodium succinate + water system at different temperatures.

\begin{tabular}{|c|c|c|c|c|c|}
\hline \multicolumn{2}{|c|}{$298.15 \mathrm{~K}$} & \multicolumn{2}{|c|}{$308.15 \mathrm{~K}$} & \multicolumn{2}{|c|}{$318.15 \mathrm{~K}$} \\
\hline $\begin{array}{l}W_{\mathrm{PEG}} \\
\%(\mathrm{w} / \mathrm{w})\end{array}$ & $\begin{array}{c}W_{S} \\
\%(w / w)\end{array}$ & $\begin{array}{c}W_{\mathrm{PEG}} \\
\%(\mathrm{w} / \mathrm{w})\end{array}$ & $\begin{array}{c}W_{S} \\
\%(\mathrm{w} / \mathrm{w})\end{array}$ & $\begin{array}{c}W_{\mathrm{PEG}} \\
\%(\mathrm{w} / \mathrm{w})\end{array}$ & $\begin{array}{c}W_{S} \\
\%(\mathrm{w} / \mathrm{w})\end{array}$ \\
\hline 41.23 & 9.05 & 39.12 & 7.51 & 41.74 & 5.18 \\
\hline 38.46 & 9.23 & 37.23 & 7.94 & 39.19 & 5.67 \\
\hline 36.45 & 9.72 & 34.58 & 8.12 & 38.33 & 5.77 \\
\hline 34.64 & 10.16 & 33.10 & 8.47 & 37.28 & 6.03 \\
\hline 33.00 & 10.56 & 31.74 & 8.80 & 35.12 & 6.34 \\
\hline 31.51 & 10.92 & 30.49 & 9.11 & 33.59 & 6.55 \\
\hline 30.15 & 11.26 & 29.33 & 9.39 & 32.51 & 6.77 \\
\hline 28.90 & 11.56 & 27.13 & 10.03 & 29.89 & 7.15 \\
\hline 27.75 & 11.84 & 26.15 & 10.31 & 28.06 & 7.55 \\
\hline 26.23 & 12.59 & 25.24 & 10.58 & 26.25 & 7.78 \\
\hline 24.86 & 13.26 & 24.39 & 10.82 & 25.33 & 8.08 \\
\hline 22.85 & 14.02 & 23.60 & 11.05 & 23.39 & 9.02 \\
\hline 21.14 & 14.66 & 22.83 & 11.30 & 22.79 & 9.42 \\
\hline 18.86 & 15.09 & 21.43 & 11.75 & 21.67 & 9.68 \\
\hline 18.14 & 15.48 & 20.20 & 12.14 & 20.66 & 9.91 \\
\hline 17.47 & 15.84 & 19.64 & 12.32 & 19.24 & 10.34 \\
\hline 16.28 & 16.50 & 18.44 & 13.15 & 18.80 & 10.48 \\
\hline 15.74 & 16.79 & 17.27 & 13.54 & 17.24 & 10.97 \\
\hline 14.32 & 17.57 & 16.36 & 13.87 & 16.88 & 11.08 \\
\hline 13.90 & 17.80 & 15.62 & 14.22 & 15.61 & 11.49 \\
\hline 13.14 & 18.22 & 14.38 & 14.89 & 15.04 & 11.66 \\
\hline 12.78 & 18.41 & 13.71 & 15.34 & 14.51 & 11.83 \\
\hline 11.22 & 19.77 & 12.52 & 15.77 & 13.79 & 12.06 \\
\hline 10.15 & 20.53 & 11.29 & 16.06 & 12.73 & 12.39 \\
\hline 9.55 & 21.55 & 10.09 & 16.87 & 11.19 & 13.06 \\
\hline 8.69 & 22.09 & 9.17 & 17.14 & 10.13 & 13.52 \\
\hline 8.11 & 23.12 & 7.96 & 18.33 & 8.29 & 13.87 \\
\hline 7.35 & 24.42 & 6.35 & 20.11 & 7.09 & 14.55 \\
\hline 5.33 & 25.76 & 5.46 & 20.86 & 5.27 & 15.34 \\
\hline 4.11 & 26.44 & 4.31 & 22.32 & 4.16 & 16.29 \\
\hline \multirow[t]{5}{*}{3.22} & 27.88 & 3.79 & 23.18 & 3.78 & 17.33 \\
\hline & & 2.59 & 24.03 & 2.85 & 17.98 \\
\hline & & 2.57 & 25.22 & 2.13 & 19.79 \\
\hline & & 1.87 & 26.29 & 2.09 & 18.88 \\
\hline & & 1.18 & 27.38 & & \\
\hline
\end{tabular}

Figure 1 reveals that there is an expansion of biphasic area as the temperature increases and it moves towards the origin. This behavior is due to the increase in salt solubility and the concentration of salt and PEG required for the formation ATPS decreases with increasing the temperature. Similar results were reported by many researchers $[24,25]$ for other ATPS at different temperatures. This kind of binodal behavior can be explained on the basis of effective excluded volume (EEV). It is the available space in a network of one component (PEG) to occupy the other component (salt); it

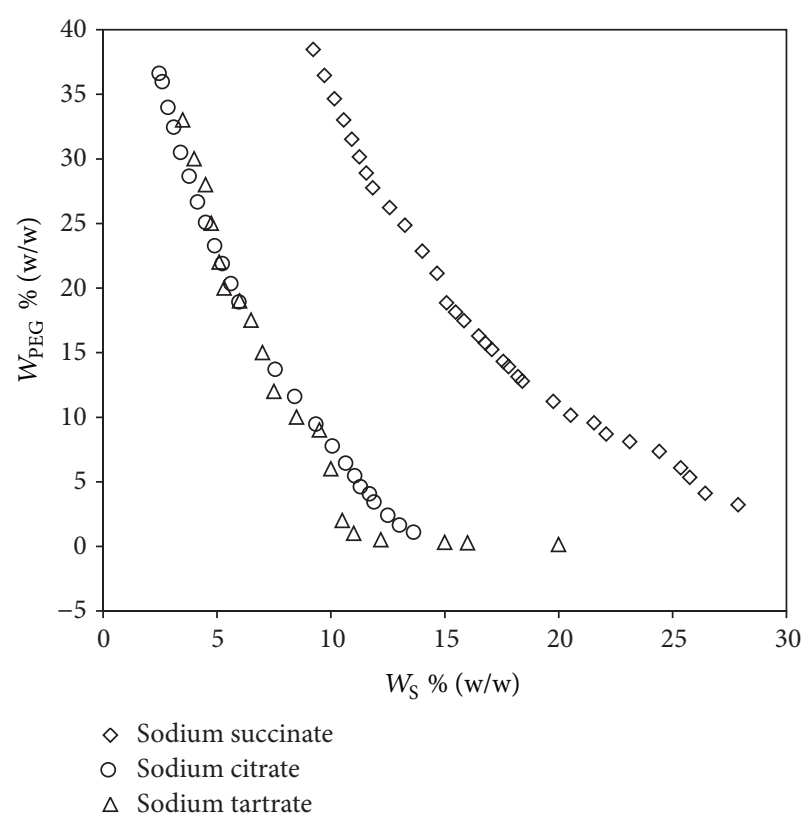

FIGURE 2: Effect of the cation on the binodal curves for the PEG 6000 $\left(W_{\mathrm{PEG}}\right)+$ salt $\left(W_{\mathrm{S}}\right)+$ water systems at $298.15 \mathrm{~K}$.

also characterizes the acceptability of a particular salt by a polymer to form an ATPS, with water as a solvent. This value is affected by the size, shape, and molecular interactions of the phase components involved in ATPS [26].

In the present work, the model (2) proposed by Guan et al. [26] which was based on statistical geometry was used to determine the EEV values. Consider

$$
\ln \left[V_{123}^{*} \frac{W_{\mathrm{PEG}}}{M_{\mathrm{PEG}}}\right]+\left[V_{123}^{*} \frac{W_{\mathrm{S}}}{M_{\mathrm{S}}}\right]=0,
$$

where $V_{123}^{*}$ is the effective excluded volume and $M_{\mathrm{PEG}}$ and $M_{\mathrm{S}}$ are the molecular weights of PEG and the sodium succinate, respectively. The EEV values were calculated by regression analysis of the model (2) and given in Table 3.

In the investigated systems it has been observed from Table 3 that EEV is relatively more at higher temperatures, indicating that salting-out strength of the salt increases with an increase in temperature. This high salting-out ability at high temperature is reflected in Figure 1 by a positional shift of binodal curve towards the left side, and thus a less concentration of salt is needed to form two-phase system. This is in accordance with the reported literature for other systems [24, 25].

3.2. Effect of Anion. In order to understand the effect of anion, the binodal curves of various salts having different anion and common sodium cation (sodium citrate, sodium tartrate, and sodium succinate) were plotted in Figure 2. The EEV values were obtained (Table 4) by calculation using the literature and experimental data. From the table it is clear that the EEV values follow the order citrate $>$ tartrate $>$ succinate, and this reveals that citrate anion has the higher valency than others and has the highest salting-out ability. Similar results were 
TABLE 2: Binodal curve coefficients of (1) for PEG $6000+$ sodium succinate + water at various temperatures.

\begin{tabular}{lcccccrr}
\hline Temperature, K & $A$ & $B$ & $C$ & $D$ & $R^{2}$ & AARD $^{*}(\%)$ & SD $^{* *}$ \\
\hline 298.15 & 247.48 & -111.43 & 14.98 & -0.09 & 0.9823 & 4.07 \\
308.15 & 178.92 & -74.87 & 8.92 & -0.04 & 0.9886 & 8.10 & 0.55 \\
318.15 & 103.12 & -25.96 & -0.97 & 0.08 & 0.9958 & 5.38 & 0.76 \\
\hline
\end{tabular}

${ }^{*}$ Average arithmetic relative deviation $(\mathrm{AARD})=\left\{\sum_{i}^{N}(\|\operatorname{Expt}-\mathrm{Cal} / \operatorname{Expt}\|) / N\right\} \times 100$.

${ }^{* *}$ Standard deviation $(\mathrm{SD})=\left\{\sum_{i}^{N}(\mathrm{Expt}-\mathrm{Cal})^{2} / N\right\}^{1 / 2}$.

TABLE 3: EEV values (2) of PEG 6000 + sodium succinate + water at different temperatures.

\begin{tabular}{lccc}
\hline Temperature, $\mathrm{K}$ & $\mathrm{EEV}(\mathrm{g} / \mathrm{mol})$ & AARD, $\%$ & SD \\
\hline 298.15 & 37.62 & 2.70 & 1.28 \\
308.15 & 43.18 & 2.18 & 1.07 \\
318.15 & 50.89 & 3.46 & 2.13 \\
\hline
\end{tabular}

TABLE 4: EEV values (2) of PEG 6000 + sodium succinate + water at $298.15 \mathrm{~K}$

\begin{tabular}{lccc}
\hline Type of salt & EEV $(\mathrm{g} / \mathrm{mol})$ & SD & Reference \\
\hline Sodium citrate & 70.79 & 4.60 & {$[33]$} \\
Sodium tartrate & 61.59 & 7.94 & {$[34]$} \\
Sodium succinate & 39.32 & 2.35 & {$[16]$} \\
Sodium succinate & 37.62 & 1.28 & This work \\
\hline
\end{tabular}

observed by Perez et al. [17]. Moreover this is in agreement with the familiar Hofmeister series [27] for anions which follows the order: citrate $>$ tartrate $>$ succinate. According to this series, the ions present in the left of the series increase the solvent surface tension and decrease the solubility of nonpolar molecules and thus have high salting-out ability. In addition to this, anions with higher valence are better saltingout agents because of their higher degree of hydration.

3.3. Tie-Line Compositions and Correlations. The equilibrium phase compositions of the two phases were related by tieline length (TLL) which is defined as the difference in concentration of phase forming components of ATPS. It can be determined by the following equation and is expressed in weight percentage $(\% \mathrm{w} / \mathrm{w})$ :

$$
\mathrm{TLL}=\sqrt{\left[W_{\mathrm{S}}^{\mathrm{T}}-W_{\mathrm{S}}^{\mathrm{B}}\right]^{2}+\left[W_{\mathrm{PEG}}^{\mathrm{T}}-W_{\mathrm{PEG}}^{\mathrm{B}}\right]^{2}}
$$

where $W_{\mathrm{S}}$ and $W_{\mathrm{PEG}}$ are the concentrations of salt and PEG, respectively, and superscripts $T$ and $B$ represent top and bottom phases, respectively. A series of TLLs in the two-phase region of the binodal curve were investigated and given in Table 5 and one set of data for $318.15 \mathrm{~K}$ is shown in Figure 3.

It is apparent from Table 5 that the increase in TLL increases the concentration of salt in the bottom phase and decreases the PEG concentration and vice versa. This is because of the increase in hydrophobicity of the phases as the TLL increases. Moreover, for the same feed compositions, the TLL increases as the temperature increases and it may be due to the increase in PEG hydrophobicity with an increase

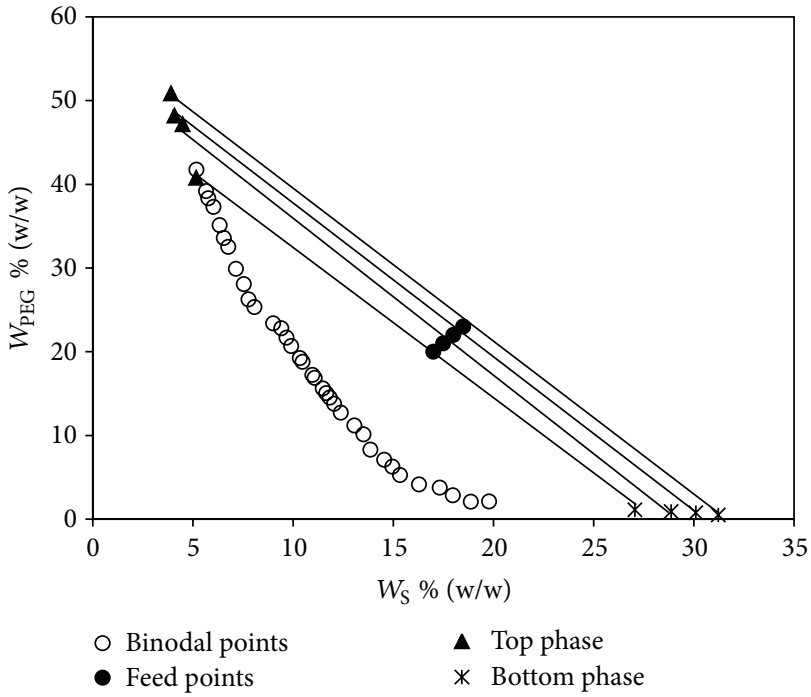

FIGURE 3: Binodal curve and tie lines for PEG $6000\left(W_{\text {PEG }}\right)+$ sodium succinate $\left(W_{\mathrm{S}}\right)+$ water system at $318.15 \mathrm{~K}$.

in temperature and the water is moved out from the polymerrich top phase to the salt-rich bottom phase [28]. For all the systems investigated, the total system composition has no significant effect upon the slope of the tie lines, which implies that they are parallel to each other, thus allowing us to know the coexisting phase compositions for any given total polymer phase-forming composition [29].

The tie-line compositions of the PEG 6000 + sodium succinate + water fitted with Othmer-Tobias equation (4) and Bancroft equation (5) [30, 31]

$$
\begin{aligned}
\left(\frac{1-W_{\mathrm{PEG}}^{t}}{W_{\mathrm{PEG}}^{t}}\right) & =K_{\mathrm{OT}}\left(\frac{1-W_{\mathrm{S}}^{b}}{W_{\mathrm{S}}^{b}}\right)^{n}, \\
\left(\frac{W_{\mathrm{W}}^{b}}{W_{\mathrm{S}}^{b}}\right) & =K_{B}\left(\frac{W_{\mathrm{W}}^{t}}{W_{\mathrm{PEG}}^{t}}\right)^{r},
\end{aligned}
$$

where $W_{\mathrm{W}}$ is the weight fraction of water and $K_{\mathrm{OT}}, n, K_{B}$, and $r$ are the fitted parameter coefficients. For the present system, these values are calculated and given in the Table 6 .

The increase in hydrophobicity of PEG with increase in temperature can be related to the salting-out effect and is usually related to the empirical equation of modified 
TABle 5: Tie-line composition for the PEG 6000 + sodium succinate + water system at different temperatures.

\begin{tabular}{|c|c|c|c|c|c|c|}
\hline \multirow{2}{*}{$\begin{array}{l}\text { TLL } \\
(\% \mathrm{w} / \mathrm{w})\end{array}$} & \multicolumn{2}{|c|}{ Feed } & \multicolumn{2}{|c|}{ Top phase } & \multicolumn{2}{|c|}{ Bottom phase } \\
\hline & $\begin{array}{c}W_{\mathrm{PEG}} \\
(\% \mathrm{w} / \mathrm{w})\end{array}$ & $\begin{array}{c}W_{S} \\
(\% \mathrm{w} / \mathrm{w})\end{array}$ & $\begin{array}{c}W_{\mathrm{PEG}} \\
(\% \mathrm{w} / \mathrm{w})\end{array}$ & $\begin{array}{c}W_{S} \\
(\% \mathrm{w} / \mathrm{w})\end{array}$ & $\begin{array}{c}W_{\mathrm{PEG}} \\
(\% \mathrm{w} / \mathrm{w})\end{array}$ & $\begin{array}{c}W_{S} \\
(\% \mathrm{w} / \mathrm{w})\end{array}$ \\
\hline \multicolumn{7}{|l|}{$298.15 \mathrm{~K}$} \\
\hline 25.28 & 20.0 & 17.0 & 30.04 & 11.21 & 7.79 & 23.21 \\
\hline 30.93 & 21.0 & 17.5 & 34.45 & 10.13 & 7.05 & 24.49 \\
\hline 38.51 & 22.0 & 18.0 & 38.21 & 9.08 & 4.17 & 27.09 \\
\hline 43.60 & 23.0 & 18.5 & 41.68 & 8.79 & 3.14 & 29.17 \\
\hline \multicolumn{7}{|l|}{$308.15 \mathrm{~K}$} \\
\hline 39.55 & 20.0 & 17.0 & 37.24 & 7.98 & 2.15 & 26.22 \\
\hline 42.43 & 21.0 & 17.5 & 39.15 & 7.53 & 1.49 & 27.07 \\
\hline 46.28 & 22.0 & 18.0 & 41.87 & 6.51 & 1.06 & 28.34 \\
\hline 50.75 & 23.0 & 18.5 & 45.09 & 6.13 & 0.64 & 30.61 \\
\hline \multicolumn{7}{|l|}{$318.15 \mathrm{~K}$} \\
\hline 45.29 & 20.0 & 17.0 & 40.78 & 5.17 & 1.13 & 27.06 \\
\hline 52.29 & 21.0 & 17.5 & 47.16 & 4.49 & 0.91 & 28.88 \\
\hline 54.10 & 22.0 & 18.0 & 48.18 & 4.09 & 0.75 & 30.11 \\
\hline 57.28 & 23.0 & 18.5 & 50.85 & 3.91 & 0.51 & 31.23 \\
\hline
\end{tabular}

TABLE 6: Values of parameters of Othmer-Tobias and Bancroft equations PEG 6000 + sodium succinate + water system for various temperatures.

\begin{tabular}{lcccccc}
\hline Temperature, $\mathrm{K}$ & $K_{\mathrm{OT}}$ & $n$ & $R^{2}$ & $K_{B}$ & $r$ & $R^{2}$ \\
\hline 298.15 & 0.346387 & 1.5587 & 0.9687 & 2.150499 & 0.5044 & 0.9762 \\
308.15 & 0.354623 & 1.4939 & 0.9875 & 2.153081 & 0.6407 & 0.9855 \\
318.15 & 0.205913 & 1.9427 & 0.9507 & 1.615751 & 0.8477 & 0.9469
\end{tabular}

TABLE 7: Values of $K_{s}$ and intercept of Setschenow-type equation (6) for the PEG 6000 + sodium succinate + water systems at various temperatures.

\begin{tabular}{lccc}
\hline Temperature, $\mathrm{K}$ & $K_{s}(\mathrm{~kg} / \mathrm{mol})$ & Intercept & $R^{2}$ \\
\hline 298.15 & 3.1809 & -0.4084 & 0.9934 \\
308.15 & 3.6436 & -0.0375 & 0.984 \\
318.15 & 3.887 & -0.6106 & 0.9565 \\
\hline
\end{tabular}

Setschenow equation [32]. The equation used has the following form:

$$
\ln \left(\frac{m_{\mathrm{PEG}}^{\mathrm{T}}}{m_{\mathrm{PEG}}^{\mathrm{B}}}\right)=K_{\mathrm{PEG}}\left(m_{\mathrm{PEG}}^{\mathrm{B}}-m_{\mathrm{PEG}}^{\mathrm{T}}\right)+K_{s}\left(m_{\mathrm{S}}^{\mathrm{B}}-m_{\mathrm{S}}^{\mathrm{T}}\right),
$$

where $K_{\mathrm{PEG}}$ and $K_{s}$ are the parameters relating the activity coefficient of PEG to its concentration and the salting-out coefficient, respectively. " $m$ " represents molality and the superscripts $\mathrm{T}$ and $\mathrm{B}$ represent top phase and bottom phase, respectively. The parameters of the previous equations were calculated based on the tie-line data and shown in Table 7 and Figure 4.

It has been observed that the salting-out coefficient $K_{s}$ value increases with increase in temperature. This is in accordance with the salting-out ability with EEV values as

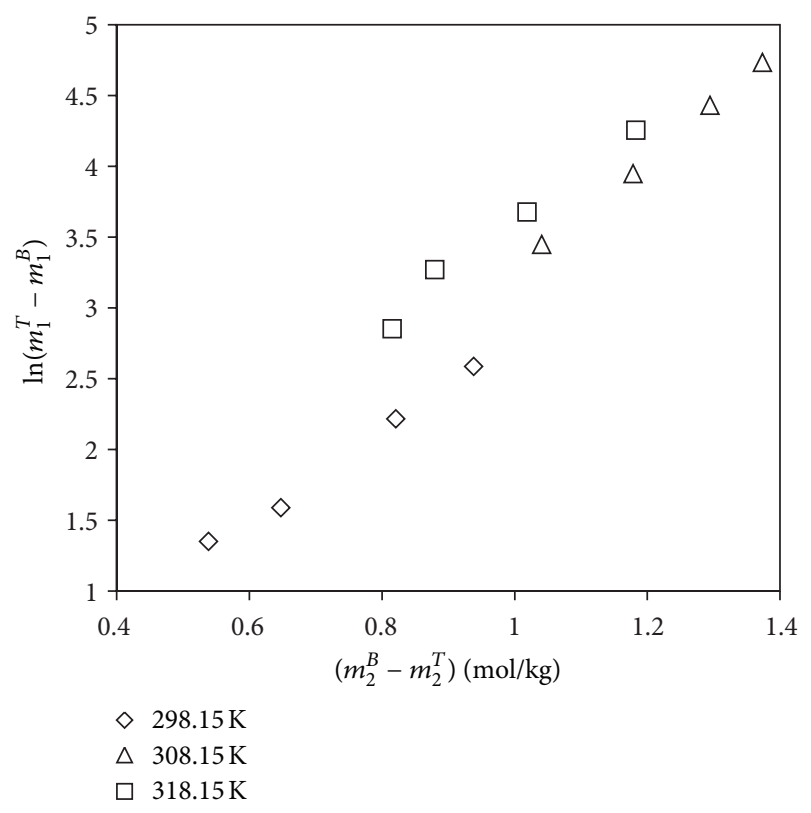

Figure 4: Setschenow-type plots for the type of salt on binodal curves for the PEG 6000 + sodium succinate + water systems for various temperatures.

described earlier. Therefore two-phase formation occurs at lower concentration of phase components at higher temperatures.

3.4. Effect of $M W$ of PEG. In order to visualize the effect of PEG molecular weight, experiments were performed at 298.15 K for PEG 10000 + SS + water and compared with PEG 6000 + SS + water system (Figure 5). It is evident from 


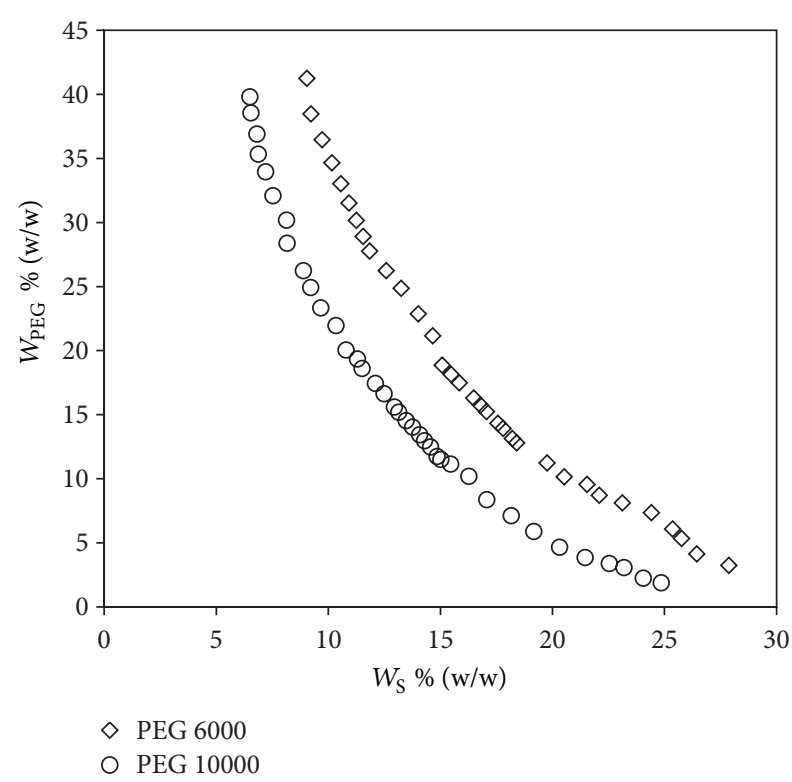

FIGURE 5: Effect of molecular weight of PEG on the binodal curve for the PEG $\left(W_{\mathrm{PEG}}\right)+$ sodium succinate $\left(W_{\mathrm{S}}\right)+$ water systems at $298.15 \mathrm{~K}$

the figure that as the MW increases the biphasic region expands and moves towards the origin thus requiring a lower concentration for phase separation. This behavior may be due to the high hydrophobicity of PEG 10000 when compared to PEG 6000 and thus a decrease in compatibility between phase components [22]. Moreover the EEV value for the present PEG 10000 + sodium succinate + water system was calculated by the procedure discussed earlier and it was found to be $53.62 \mathrm{~g} / \mathrm{mol}$ which was lesser than PEG $6000+$ sodium succinate + water system $(37.62 \mathrm{~g} / \mathrm{mol})$. This confirms the higher salting-out characteristics of higher MW PEG [9].

\section{Conclusions}

The binodal curves for PEG 6000 + sodium succinate + water system at various temperatures $(298.15 \mathrm{~K}, 308.15 \mathrm{~K}$, and $318.15 \mathrm{~K}$ ) were constructed and satisfactorily fitted with a non-linear equation. Increase in temperature resulted in the expansion of the binodal area and increase in effective excluded volume values because of high salting-out ability at high temperatures. The effect of anion on the location of binodal curve was also discussed and compared with the literature which followed the Hofmeister series: citrate $>$ tartrate $>$ succinate. The tie-line compositions were correlated with Othmer and Tobias equations and salting-out ability at various temperatures were fitted by Setschenow-type equation. The salting-out coefficient values increased with an increase in temperature similar to EEV values. The effect of PEG 10000 on the location of binodal curve was also verified.

\section{Conflict of Interests}

The authors declare no conflict of interests.

\section{Acknowledgment}

The authors gratefully acknowledge the Department of Biotechnology, MIT, Manipal University, for providing the facilities to carry out the research work.

\section{References}

[1] P. A. Albertsson, Partitioning of Cell Particles and Macromolecules, John Wiley \& Sons, New York, NY, USA, 3rd edition, 1987.

[2] K. Naganagouda and V. H. Mulimani, "Aqueous two-phase extraction (ATPE): an attractive and economically viable technology for downstream processing of Aspergillus oryzae $\alpha$ galactosidase," Process Biochemistry, vol. 43, no. 11, pp. 12931299, 2008.

[3] I. P. Trindade, M. M. Diogo, D. M. F. Prazeres, and J. C. Marcos, "Purification of plasmid DNA vectors by aqueous two-phase extraction and hydrophobic interaction chromatography," Journal of Chromatography A, vol. 1082, no. 2, pp. 176-184, 2005.

[4] O. Aguilar, V. Albiter, L. Serrano-Carreón, and M. Rito-Palomares, "Direct comparison between ion-exchange chromatography and aqueous two-phase processes for the partial purification of penicillin acylase produced by E. coli," Journal of Chromatography B, vol. 835, no. 1-2, pp. 77-83, 2006.

[5] D. Z. Ivetic, M. B. Sciban, V. M. Vasic, D. V. Kukic, J. M. Prodanovic, and M. G. Antov, "Evaluation of possibility of textile dye removal from wastewater by aqueous two-phase extraction," Desalination and Water Treatment, vol. 51, pp. 1-6, 2012.

[6] S. H. Ammar, W. A. W. Abdul-Nabi, and M. K. Rasheed, "Extraction of $\mathrm{Zn}$ (II) and Cu (II) Ions Using PEG, (300) - KCl salt aqueous two-phase systems," Al-Khwarizmi Engineering Journal, vol. 7, pp. 68-674, 2011.

[7] S. Saravanan, J. R. Rao, T. Murugesan, B. U. Nair, and T. Ramasami, "Recovery of value-added globular proteins from tannery wastewaters using PEG-salt aqueous two-phase systems," Journal of Chemical Technology and Biotechnology, vol. 81, no. 11, pp. 1814-1819, 2006.

[8] J. Raghava Rao and B. U. Nair, "Novel approach towards recovery of glycosaminoglycans from tannery wastewater," Bioresource Technology, vol. 102, no. 2, pp. 872-878, 2011.

[9] R. Iyyaswami, P. D. Belur, B. Girish, and V. H. Nagaraj, "Development and evaluation of PEG-lithium citrate salt based aqueous two phase system and its application in partitioning of proteins from fish industry effluent," Separation Science and Technology, vol. 47, no. 4, pp. 591-598, 2012.

[10] J. Zhang, Y. Wang, and Q. Peng, "Phase behavior of aqueous two-phase systems of cationic and anionic surfactants and their application to theanine extraction," Korean Journal of Chemical Engineering, vol. 30, no. 6, pp. 1284-1288, 2013.

[11] S. Raja and V. R. Murty, "Development and evaluation of environmentally benign aqueous two phase systems for the recovery of proteins from tannery waste water," ISRN Chemical Engineering, vol. 2012, Article ID 290471, 9 pages, 2012.

[12] S. Raja and V. R. Murty, "Optimization of aqueous two-phase systems for the recovery of soluble proteins from tannery wastewater using response surface methodology," Journal of Engineering, vol. 2013, Article ID 217483, 10 pages, 2013.

[13] S. Raja, V. R. Murty, V. Thivaharan, V. Rajasekar, and V. Ramesh, "Aqueous two phase systems for the recovery of biomoleculesa review," Science and Technology, vol. 1, pp. 7-16, 2011.

[14] F. Rahimpour, F. Feyzi, S. Maghsoudi, and R. Hatti-Kaul, "Purification of plasmid DNA with polymer-salt aqueous two-phase 
system: optimization using response surface methodology," Biotechnology and Bioengineering, vol. 95, no. 4, pp. 627-637, 2006.

[15] K. P. Ananthapadmanabhan and E. D. Goddard, "Aqueous biphase formation in polyethylene oxide-inorganic salt systems," Langmuir, vol. 3, no. 1, pp. 25-31, 1987.

[16] M. T. Zafarani-Moattar and S. Hamzehzadeh, "Liquid-liquid equilibria of aqueous two-phase systems containing polyethylene glycol and sodium succinate or sodium formate," Computer Coupling of Phase Diagrams and Thermochemistry, vol. 29, no. 1, pp. 1-6, 2005.

[17] B. Perez, L. P. Malpiedi, G. Tubío, B. Nerli, P. de Alcântara, and P. Filho, "Experimental determination and thermodynamic modeling of phase equilibrium and protein partitioning in aqueous two-phase systems containing biodegradable salts," Journal of Chemical Thermodynamics, vol. 56, pp. 136-143, 2013.

[18] J. Benavides and M. Rito-Palomares, "Practical experiences from the development of aqueous two-phase processes for the recovery of high value biological products," Journal of Chemical Technology and Biotechnology, vol. 83, no. 2, pp. 133-142, 2008.

[19] R. Hatti-Kaul, Aqueous Two Phase Systems: Methods and Protocols, Humana Press, Totowa, NJ, USA, 2000.

[20] J. C. Merchuk, B. A. Andrews, and J. A. Asenjo, "Aqueous twophase systems for protein separation studies on phase inversion," Journal of Chromatography B, vol. 711, no. 1-2, pp. 285293, 1998.

[21] S. Saravanan, J. A. Reena, J. R. Rao, T. Murugesan, and B. U. Nair, "Phase equilibrium compositions, densities, and viscosities of aqueous two-phase poly(ethylene glycol) + poly(acrylic acid) system at various temperatures," Journal of Chemical and Engineering Data, vol. 51, no. 4, pp. 1246-1249, 2006.

[22] M. Jayapal, I. Regupathi, and T. Murugesan, "Liquid-liquid equilibrium of poly(ethylene glycol) $2000+$ potassium citrate + water at $(25,35 \text {, and } 45)^{\circ} \mathrm{C}$," Journal of Chemical and Engineering Data, vol. 52, no. 1, pp. 56-59, 2007.

[23] M. Hu, Q. Zhai, Y. Jiang, L. Jin, and Z. Liu, "Liquid-liquid and liquid-liquid-solid equilibrium in PEG $+\mathrm{Cs}_{2} \mathrm{SO}_{4}+\mathrm{H}_{2} \mathrm{O}$," Journal of Chemical and Engineering Data, vol. 49, no. 5, pp. 14401443, 2004.

[24] R. Govindarajan, K. Divya, and M. Perumalsamy, "Phase behavior and density for binary and ternary solutions of PEG, 4000 + triammonium citrate + water aqueous two phase systems at different temperatures," Journal of Chemical Engineering Data, vol. 58, no. 2, pp. 315-321, 2013.

[25] I. Regupathi, C. K. Srikanth, and N. Sindhu, "Liquid-liquid equilibrium of poly(ethylene glycol) $2000+$ diammonium hydrogen citrate + water system at different temperatures," Journal of Chemical and Engineering Data, vol. 56, no. 9, pp. 3643-3650, 2011.

[26] Y. Guan, T. H. Lilley, and T. E. Treffry, "A new excluded volume theory and its application to the coexistence curves of aqueous polymer two-phase systems," Macromolecules, vol. 26, no. 15, pp. 3971-3979, 1993.

[27] R. A. Curtis and L. Lue, "A molecular approach to bioseparations: protein-protein and protein-salt interactions," Chemical Engineering Science, vol. 61, no. 3, pp. 907-923, 2006.

[28] R. Sadeghi and R. Golabiazar, "Thermodynamics of phase equilibria of aqueous poly(ethylene glycol) + sodium tungstate two-phase systems," Journal of Chemical and Engineering Data, vol. 55, no. 1, pp. 74-79, 2010.

[29] G. Tubío, L. Pellegrini, B. B. Nerli, and G. A. Picó, "Liquidliquid equilibria of aqueous two-phase systems containing poly(ethylene glycols) of different molecular weight and sodium citrate," Journal of Chemical and Engineering Data, vol. 51, no. 1, pp. 209-212, 2006.

[30] D. F. Othmer and P. E. Tobias, "Liquid-liquid extraction data: toluene and acetaldehyde systems," Industrial and Engineering Chemistry, vol. 34, no. 6, pp. 690-692, 1942.

[31] P. González-Tello, F. Camacho, G. Blázquez, and F. J. Alarcón, "Liquid-liquid equilibrium in the system poly(ethylene glycol) $+\mathrm{MgSO}_{4}+\mathrm{H}_{2} \mathrm{O}$ at $298 \mathrm{~K}$," Journal of Chemical and Engineering Data, vol. 41, no. 6, pp. 1333-1336, 1996.

[32] M. J. Hey, D. P. Jackson, and H. Yan, “The salting-out effect and phase separation in aqueous solutions of electrolytes and poly(ethylene glycol)," Polymer, vol. 46, no. 8, pp. 2567-2572, 2005.

[33] M. T. Zafarani-Moattar, R. Sadeghi, and A. A. Hamidi, "Liquidliquid equilibria of an aqueous two-phase system containing polyethylene glycol and sodium citrate: experiment and correlation," Fluid Phase Equilibria, vol. 219, no. 2, pp. 149-155, 2004.

[34] L. P. Malpiedi, C. Fernández, G. Picó, and B. Nerli, "Liquidliquid equilibrium phase diagrams of polyethyleneglycol + sodium tartrate + water two-phase systems," Journal of Chemical and Engineering Data, vol. 53, no. 5, pp. 1175-1178, 2008. 

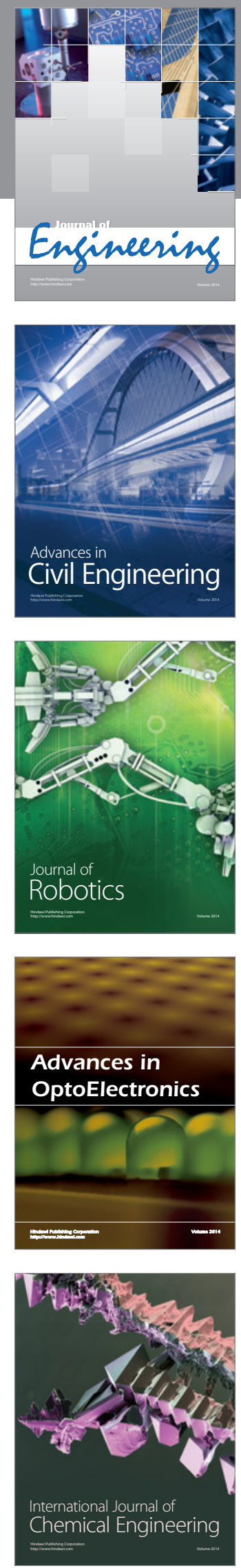

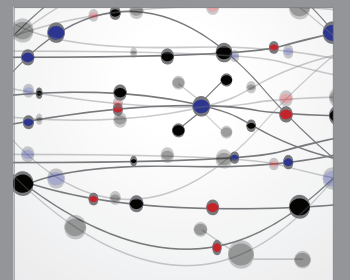

The Scientific World Journal
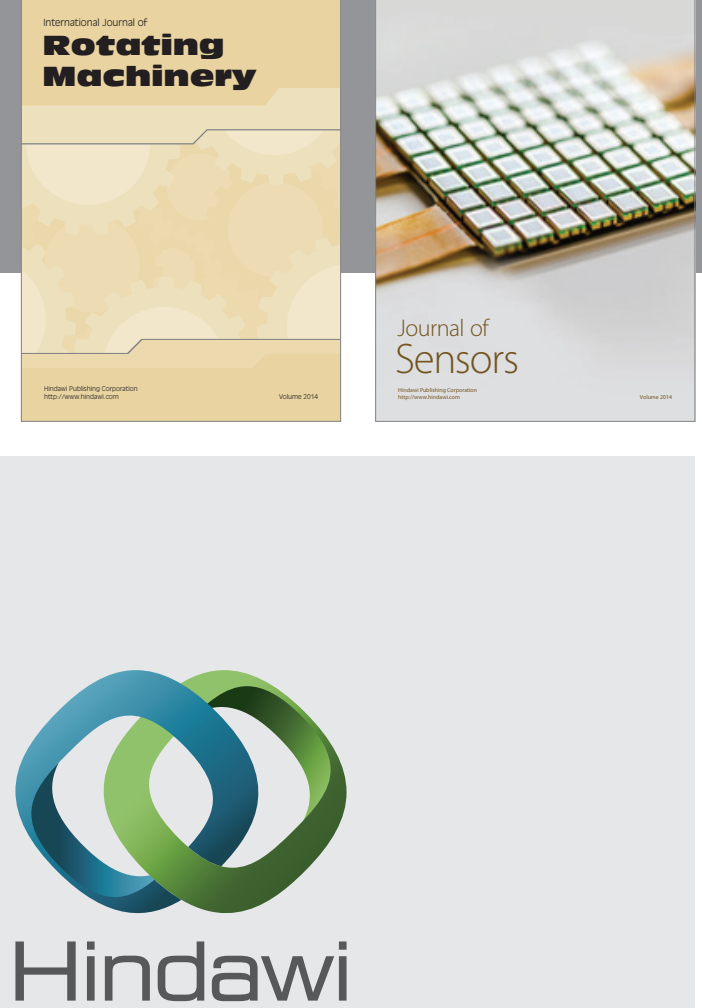

Submit your manuscripts at http://www.hindawi.com
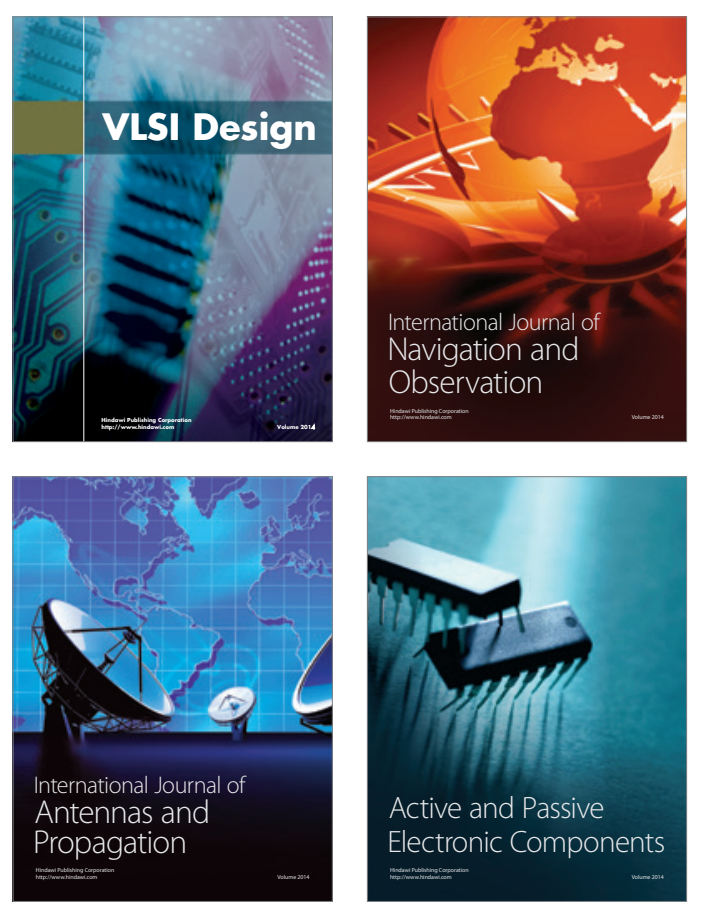
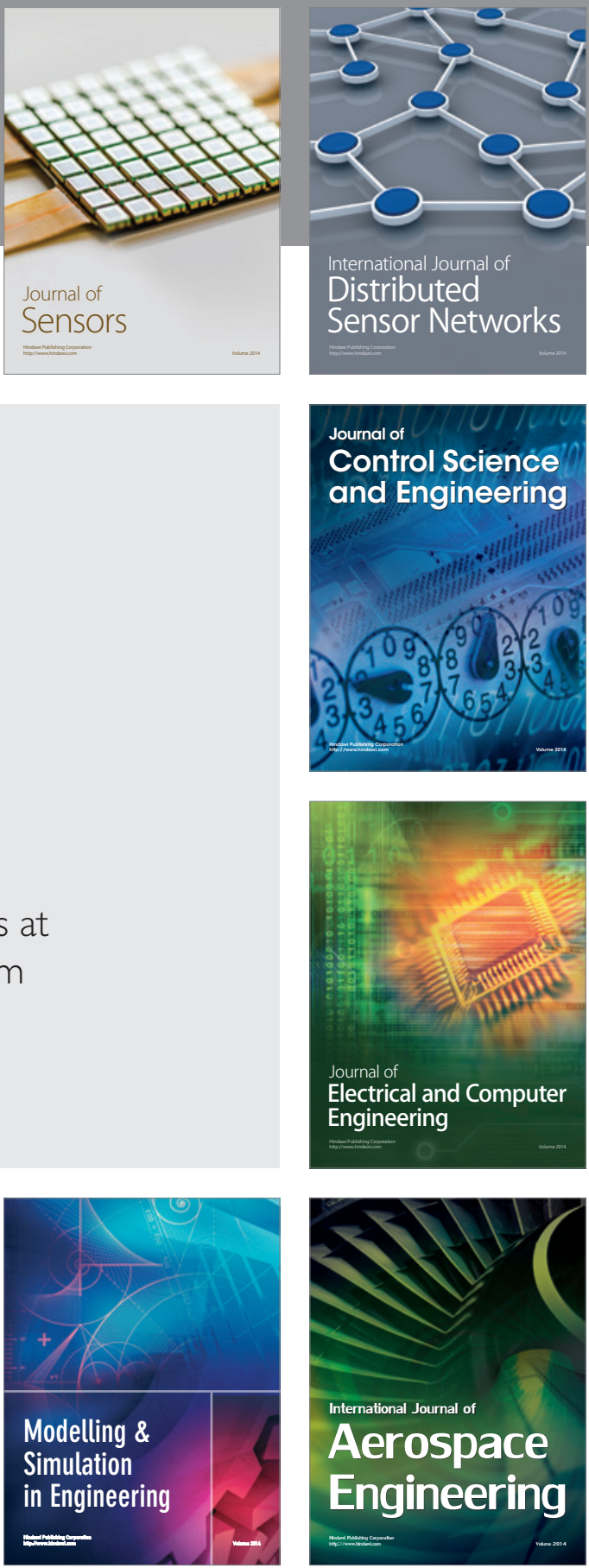

Journal of

Control Science

and Engineering
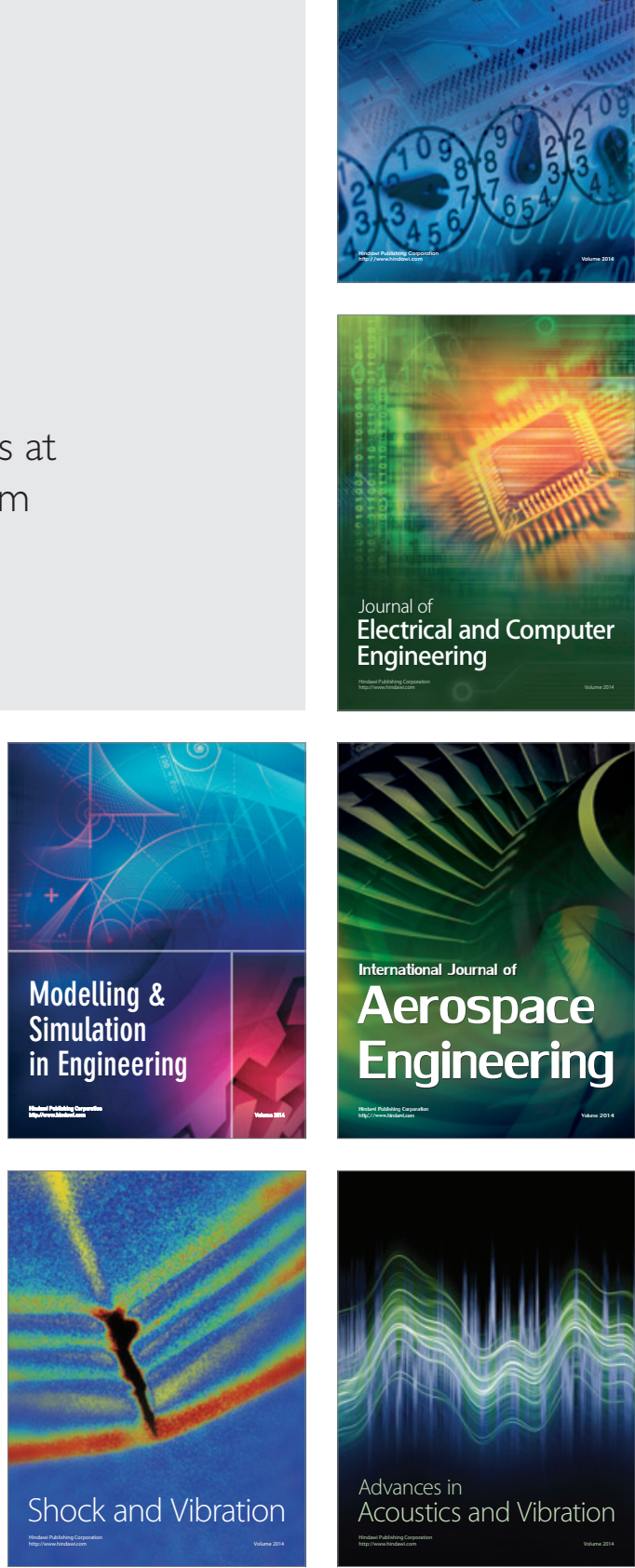